\title{
A SOCIEDADE CIVIL ORGANIZADA E A LUTA PELO RECONHECIMENTO DAS LIBERDADES FUNDAMENTAIS DURANTE OS PROCESSOS DE NEGOCIAÇÃO DA PAZ: LIÇÕES DA GUERRA CIVIL NA SERRA LEOA E DO ACORDO DE PAZ DE LOMÉ
}

\author{
CIVIL SOCIETY AND THE FIGHT FOR RECOGNITION OF THE FUNDAMENTAL \\ LIBERTIES DURING PEACE NEGOTIATION PROCESSES: LESSONS FROM THE CIVIL \\ WAR IN SIERRA LEONE AND FROM THE LOMÉ PEACE ACCORD
}

\author{
Erick da Luz Scherf \\ Rodrigo Milindre Gonzalez
}

\begin{abstract}
Resumo
O conflito armado que durou onze anos na Serra Leoa foi caracterizado pela extrema brutalidade e violações generalizadas dos direitos humanos, principalmente, contra civis. Portanto, tem-se como objetivos identificar qual foi o grau de importância da sociedade civil organizada na luta pelo reconhecimento das liberdades fundamentais durante os processos de negociação da paz na Serra Leoa e na posterior formalização do Acordo de Lomé, que formalmente pôs término ao conflito. Assim como, analisar se, tais liberdades foram alcançadas materialmente ou não, no contexto social serra-leonês. O método de pesquisa fora o indutivo e o mecanismos de pesquisa utilizado foi o bibliográfico. Em suma, fora possível constatar que a sociedade civil organizada na Serra Leoa, principalmente as ONGs de direitos humanos, tiveram papel importante durante os processos de negociação da paz e cessação das hostilidades, além de forçarem a pauta de direitos humanos durante estes processos, conseguiram fazer com que as partes do Acordo de Paz Lomé reconhecessem e positivassem por meio deste instrumento um corpo de liberdades e direitos fundamentais bem estabelecido. Porém, identificou-se também que as desigualdades socioeconômicas estruturais no país dificultam a transposição das liberdades do plano formal do direito para o plano material da vida em sociedade.
\end{abstract}

Palavres Chave: Sociedade Civil Organizada. Liberdades Fundamentais. Negociação da Paz. Serra Leoa. Acordo de Lomé.

\section{Abstract}

The 11-year armed conflict in Sierra Leone was characterized by extreme brutality and widespread violations of human rights, particularly against civilians. Therefore, the aim is to identify the degree of importance of the organized civil society in the struggle for the recognition of fundamental freedoms during peace negotiations in Sierra Leone and the subsequent formalization of the Lomé Agreement, which formally ended the conflict. As well as, analyze if such liberties were reached materially or not, in the social context Sierra Leone. The research method was the inductive and the search mechanism used was the bibliographic one. In sum, it was possible to note that the organized civil society in Sierra Leone, mainly human rights NGOs, played an important role during peace negotiation and cessation of hostilities, as well as forcing the human rights agenda during these processes, ensuring that the parties of the Lomé Peace Agreement recognized and affirmed in this instrument a well-established body of fundamental freedoms and rights. However, it has also been identified that structural socio-economic inequalities in the country make it difficult to translate the freedoms from the formal plan of law to the material plan of life in society. 
Key words: Organized Civil Society. Fundamental Liberties. Peace Negotiation. Sierra Leone. Lomé Peace Agreement.

\section{INTRODUÇÃO}

Longe de ser um hiato de não-derramamento de sangue, como o nome sugere, o período da Guerra Fria que se seguiu à Segunda Guerra Mundial testemunhou, na verdade, um grande número de novos conflitos, que surgiram sob o pano de fundo da descolonização e da polarização (BERNARD, 2015). O modelo dominante de conflito não era mais o de uma 'guerra industrial' entre duas tropas enfrentandose no front, ou o cenário de aviões e tanques militares que por muito tempo recheou o imaginário das sociedades afetadas pelas duas Grandes Guerras. O principal local no qual o conflito nas relações internacionais tomaria lugar era no cenário interno, principalmente, mas não exclusivamente, entre grupos armados locais contra potências estrangeiras (BERNARD, 2015).

Sem embargo, o período do pós-Guerra Fria, representaria também, um aumento no número de conflitos no cenário internacional e causaria mudanças no próprio modo como a guerra era até então concebida. Diferentemente das aspirações liberais das potências ocidentais, que acreditavam que com a queda do socialismo real e o desmantelamento da antiga União Soviética alcançariam a tão sonhada paz, - com o resgate da filosofia kantiana da paz perpétua e da recente tese do fim da História de Fukuyama ${ }^{1}$ esta não passaria de uma 'lua-de-mel' que durou pouco tempo, na concepção de Ramonet (1999). O autor cunhou o termo "geopolítica do caos" para representar as características da Nova Ordem Mundial que surgia no horizonte liberal, ordem na qual seria marcada, contraditoriamente, pela desordem (RAMONET, 1999).

Assim como afirmara Duiker (2010), a onda de otimismo que acompanhou o fim da Guerra Fria foi muito breve, após um curto período de euforia, logo ficou claro que se libertariam as forças que vinham sendo controladas pela rigidez ideológica da Guerra Fria. Ou seja, a "era do conflito" que por muito tempo caracterizou o século XX não chegara ao fim: estava simplesmente no processo de tomar uma forma diferente (DUIKER, 2010). Esta nova forma se personificou, em grande parte, em conflitos intra-estatais. Como apontou Ramonet, no final do século XX "a maioria dos conflitos (Argélia, Albânia, Bósnia, Chechênia, Curdistão, Afeganistão, Chiapas, Sudão, Libéria, Congo-Zaire, Ruanda etc.) são conflitos internos, que opõem um poder central a uma fração de sua própria população" (RAMONET, 1999, p. 7-8).

Não obstante, entende-se que estes conflitos, que surgem no pós-Guerra Fria e banham de sangue principalmente os países que estão localizados na periferia do sistema internacional no erigir desta

${ }^{1}$ Fukuyama defende a ideia de que a humanidade chegou ao ponto final de sua evolução ideológica a partir do triunfo da democracia liberal sobre o fascismo e, mais tardiamente, sobre o comunismo. 
nova ordem (sendo estes, principalmente, mas sem caráter exclusivo os países do Leste Europeu, da África e Ásia), possuem raízes muito maiores e mais complexas do que se imagina.

O continente africano (região onde o país no qual é objeto de estudo dessa pesquisa se localiza), por exemplo, foi forçado a adotar o modelo de Estado Moderno através dos processos do imperialismo e do colonialismo, processos que marginalmente integravam os Estados africanos na economia política internacional - principalmente por intermédio dos interesse dos Estados colonizadores - como fornecedores de matérias-primas para a produção industrial e mercados para escoamento de seus produtos (AKUDE, 2007).

Porém, ao contrário do que se esperava, a descolonização não superou completamente as antigas estruturas de dominação colonial, e, em vários países do continente, houve transferência do poder político para elites políticas que nasceram e foram criadas para servir, primordialmente, aos interesses coloniais (AKUDE, 2007).

É neste contexto, então, de transição inadequada ao sistema moderno estatal e de transferência de poder político às elites africanas no contexto pós-colonial que a República da Serra Leoa (país da África Ocidental) mergulhará no conflito que interromperia o processo de construção do Estado e desintegraria o país no período de 1991 a 2002, no qual fora predominantemente, mas não exclusivamente, liderado pela Frente Revolucionária Unida (FRU), sob comando de Foday Sankoh (ASANGNA, 2017).

Consoante à Human Rights Watch², o conflito armado que durou onze anos na Serra Leoa foi caracterizado pela extrema brutalidade e violações generalizadas dos direitos humanos, principalmente, contra civis. A maioria dos crimes foi perpetrada por rebeldes do Conselho Revolucionário das Forças Armadas (AFRC) e da FRU. No entanto, as forças do governo e seus aliados, especialmente as Forças de Defesa Civil (FDC), também cometeram crimes graves e durante o conflito, dezenas de milhares de civis foram mortos e até um quarto da população foi deslocada³.

Assim sendo, o conflito armado interno na Serra Leoa é uma importante peça no quebra-cabeça da história turbulenta não só do país, mas de todo o continente no que concerne ao período pósindependência africana, que fora marcado por diversos antagonismos e disputas de poder que possuem raiz, principalmente, na herança colonial da região.

Conforme explicita o relatório de 2011 do Escritório do Alto Comissário das Nações Unidas para os Direitos Humanos (EACNUDH)4, nas últimas décadas, o conflito armado destruiu a vida de milhões de civis. Graves violações do direito internacional humanitário e do direito internacional dos direitos humanos são comuns em muitos conflitos armados. Em certas circunstâncias, algumas dessas violações podem até constituir genocídio, crimes de guerra ou crimes contra a humanidade.

2Disponível em: <https://www.hrw.org/news/2012/04/11/armed-conflict-sierra-leone> Acesso em: 20 abr. 2018. 3Disponivel em: <https://www.hrw.org/news/2012/04/11/armed-conflict-sierra-leone> Acesso em: 20 abr. 2018.

4Disponivel em: <http://www.ohchr.org/Documents/Publications/HR_in_armed_conflict.pdf> Acesso em: 20 abr. 2018. 
Para o EACNUDH5, ao longo dos anos, a Assembleia Geral, a Comissão de Direitos Humanos e, mais recentemente, o Conselho de Direitos Humanos consideraram que, em conflitos armados, as partes no conflito têm obrigações legalmente vinculantes em relação aos direitos das pessoas afetadas pelo conflito. Porém, não será o escopo desta pesquisa analisar as eventuais violações ao direito internacional humanitário ou ao direito internacional dos direitos humanos durante o conflito em si, mas sim, o papel destes corpos jurídicos no cenário pós-conflito.

Sem embargo, mesmo apesar da extensão temporal do conflito, das diversas violações de direitos humanos e do cenário de instabilidade política pós-independência da República da Serra Leoa, há que se destacar a importância dos processos de negociação da paz e de restituição dos direitos lesados durante o conflito, que culminaram no Acordo de Paz de Lomé, de 1999. Segundo o Conselho Internacional de Política de Direitos Humanos (2006), a Parte V do Acordo estabeleceu disposições substantivas para questões humanitárias, de direitos humanos e de direitos socioeconômicos.

O Acordo de Lomé previa um certo número de organismos de acompanhamento e execução das normativas relativas aos direitos humanos. Em particular, reconheceu a falta de supervisão dedicada a estes e, portanto, o Comitê de Direitos Humanos estabeleceu um mecanismo de rastreamento de violações. Muito disso se deve à mobilização de ONGs de direitos humanos e mecanismos locais (o que ocasionalmente chamaremos de sociedade civil organizada) durante o final da década de 1990, que tiveram uma parcela considerável de responsabilidade pela inclusão, principalmente, das liberdades fundamentais ${ }^{6}$ no Acordo de Lomé (CONSELHO INTERNACIONAL DE POLÍTICA DE DIREITOS HUMANOS, 2006).

É a partir deste contexto que se desenvolverá esta pesquisa. Portanto, tem-se como objetivos identificar qual foi o grau de importância da sociedade civil organizada na luta pelo reconhecimento das liberdades fundamentais durante os processos de negociação da paz na Serra Leoa e na posterior formalização do Acordo de Lomé, assim como, analisar se tais liberdades foram alcançadas materialmente, ou não, no contexto social serra-leonês. O método de pesquisa fora o indutivo e o mecanismos de pesquisa utilizado foi o bibliográfico.

\section{CONTEXTUALIZAÇÃO HISTÓRICA ACERCA DA REPÚBLICA DA SERRA LEOA E DO CONFLITO INTERNO ARMADO (1991-2002):}

A história moderna do continente africano fora eminentemente marcada pelo colonialismo e pelos antagonismos que esse sistema gerou, que acabam se refletindo na atual situação política, social e econômica do continente, mesmo após os processos de descolonização. Sem embargo, a partir do contexto histórico dos processos de colonização e das lutas pela emancipação do continente africano,

5Disponível em: <http://www.ohchr.org/Documents/Publications/HR_in_armed_conflict.pdf> Acesso em: 20 abr. 2018.

${ }^{6}$ Especialmente o direito à vida, liberdade, a proibição da tortura, o direito a um julgamento justo, a liberdade de consciência, expressão e associação. 
deve-se entender a trajetória histórica da Serra Leoa nessa região - exercício imprescindível para a melhor compreensão futura do surgimento do conflito que assolaria o país, em 1991, e seus desmantelamentos posteriores.

Oficialmente denominada de "República da Serra Leoa (RSL)", o país se localiza na África Ocidental, na fronteira com o Oceano Atlântico, entre a Guiné e a Libéria (ver Imagem 1). A atual capital é a cidade de Freetown, e o atual presidente é o Sr. Julius Maada, que ocupa o cargo desde 4 de abril de 2018, como chefe de Estado e chefe de Governo.

Imagem 1: Mapa político da Serra Leoa e visualização de suas díades fronteiriças.

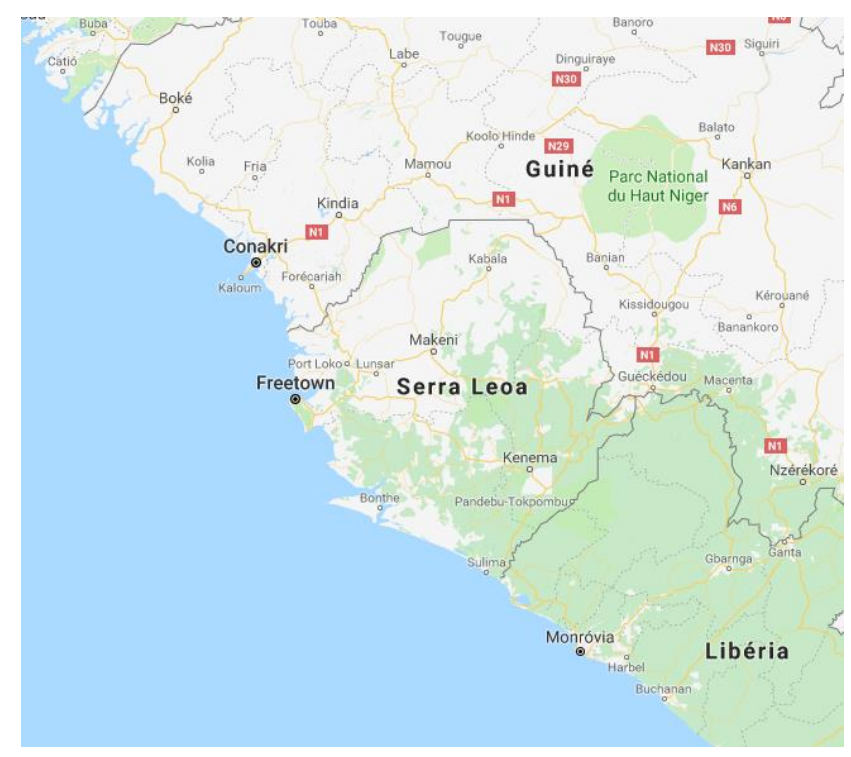

Fonte: Google Maps, 2018.

Apesar de muitos arqueólogos terem identificado sinais de habitação humana na região da Serra Leoa há milhares de anos, a historiografia tradicional tende a tratar a composição humana daquele território como resultado de diferentes ondas de imigração, porém, acredita-se que, principalmente devido a perpetuação linguística, a África Ocidental tenha sido ocupada desde um período muito anterior ao século XV (FYFE, 1987).

Todavia, fora a partir do século XV que a região se tornou aberta para o comércio e o movimento de pessoas. No século XVIII, mais precisamente em 1787, a região foi ocupada por colonizadores ingleses e, em 1792, por colonos da Nova Escócia, até que os europeus tivessem usurpado completamente a soberania política do território ocupado quando este se tornou um protetorado da Coroa Britânica em 1808 (FYFE, 1987).

Nos primeiros cem anos, de 1787 a 1887, estabeleceu-se o que seria conhecida hoje enquanto comunidade negra "Krio". Seus membros foram trazidos de outras regiões da África, principalmente da África Oriental, e sua língua e cultura nasceram da necessidade de se criar uma identidade comum, por 
meio da qual as pessoas, por mais diferente que fossem, pudessem compartilhar valores em comum, principalmente a noção de pertencimento (FYFE, 1987).

Com a tarefa da integração política mais ou menos completa, e o crescimento econômico em níveis positivos (devido principalmente às atividades comerciais de exportação), várias pessoas puderam ascender na estrutura social daquela época. Consequentemente, alguns passaram a adotar alguns hábitos dos colonizadores, até mesmo construindo casas bem mobilhadas e suas crianças frequentaram as escolas fundadas por missionários, surgindo aí uma nova comunidade com sua própria identidade e cultura (FYFE, 1987).

O ano de 1887, centenário da ocupação estrangeira, pode representar um ponto de virada simbólico na história de Serra Leoa e da África. Os governos da Europa, tendo completado os primeiros estágios de sua partição, estavam prontos para o próximo estágio. Ele deveria ser seguido na África Ocidental Britânica pela introdução do governo racial. Nos anos vindouros, os aspirantes a Krios e seus pares negros em outros lugares seriam expulsos dos altos cargos oficiais que haviam ocupado e seriam substituídos pelos brancos.

Em 1887, os africanos detinham quase metade dos cargos seniors no serviço governamental de Serra Leoa. Nos trinta anos seguintes, eles deteriam apenas um em dez destes cargos. Na Serra Leoa, como em toda a África Ocidental Britânica, a autoridade deveria basear-se num princípio racial simples: "o branco dá ordens e negro o obedece" (FYFE, 1987).

O protetorado britânico foi oficialmente proclamado sobre a área em 1896, e a estratégia colonial era manter o país dividido: brancos divididos dos negros; Colônia do Protetorado; "tribo" de "tribo"; e "cacicado" de "cacicado". O poder político passou completamente para as mãos dos brancos e os Krios foram totalmente excluídos, além disso, a estereotipização negativa deste grupo tornou-se a sabedoria convencional dos funcionários brancos - e posteriormente, dos brancos em geral (FYFE, 1987).

Contra os Krios, o governo apoiou os povos do Protetorado, cujas próprias divisões foram cuidadosamente fomentadas e exacerbadas. Como em todos os lugares da África Ocidental Britânica, a política colonial foi concebida para se adequar à conveniência dos funcionários administrativos e permitirIhes uma vida tranquila, e todo esforço foi feito para preservar essas distinções dentro da população da Serra Leoa e manter seus povos polarizados em oposição uns ao outros (FYFE, 1987).

Após a Segunda Guerra Mundial, o governo britânico cedeu às demandas nacionalistas na Serra Leoa, como em outras partes da África Ocidental. Instituições democráticas foram apressadamente constituídas. A pequena minoria crioula (Krio) esperava consolidar politicamente seus direitos, mas a constituição de 1951 deu o controle à maioria. O governo eleito foi liderado por Milton (mais tarde, Sir Milton) Margai, do Partido do Povo de Serra Leoa. Durante a década de 1950, instituições parlamentares sob o padrão britânico foram introduzidas em etapas. A última etapa foi alcançada em 27 de abril de 1961, 
quando a Serra Leoa se tornou-se um estado independente dentro da Commonwealth (FYFE; SESAY; NICOL, 2018).

Entretanto, como bem explicita Fyfe (1987), apesar de eventualmente o caminho ter sido aberto para uma transferência de poder britânica para um governo africano, nenhum governo poderia realmente representar esses povos fragmentados em mais do que no plano formal. O legado colonial de divisão descartou a possibilidade de transferência do poder para um governo que proporcionasse a unidade nacional. Em vão, os líderes do Krio imploraram por algum reconhecimento de seu status constitucional.

O Partido do Povo de Serra Leoa, o partido da maioria, para o qual o governo foi transferido na independência, representou o Protetorado. Embora alguns Krios pertenciam a ele, sua presença não conseguia conciliar animosidades há tanto tempo acalentadas, nem mascarar a sensação de triunfo no Protetorado por ter finalmente derrotado um inimigo. A independência política não trouxe mudanças estruturais, pelo contrário, a Serra Leoa permaneceu o mesmo país fragmentado que estava sob o domínio colonial há pouco (FYFE, 1987).

Para Harris (2014), a declaração de independência foi realmente importante, mas os anos seguintes, de 1961 a 1968, puderam ser facilmente vistos como o período político mais crucial na história da Serra Leoa. Neste curto espaço de tempo, o primeiro líder do Partido Popular de Serra Leoa (PPSL) e do país em si, Milton Margai, morreu e Albert Margai assumiu o seu lugar. Eleições regulares foram realizadas e surpreendentemente, em 1967, a oposição, o Congresso de Todas as Pessoas (CTP), saiu vitoriosa, um evento quase sem precedentes na África na época. As eleições mais limpas e honestas da Serra Leoa ocorreram no final dos anos 1950 e início e meados da década de 1960, consideradas por alguns como um 'modelo de competição multipartidária democrática' (HARRIS, 2014).

Entretanto, em 1966, Albert em um movimento que não estava em descompasso com outros eventos na África e no resto do mundo durante contexto da Guerra Fria, tentou, mas não conseguiu, introduzir a legislação de partido único. A tentativa dele e o fracasso em introduzir o Estado de partido único e, de fato, em certo ponto, uma república presidencial, foi uma parte da derrota, mas haviam muitos outros componentes.

Pode-se notar primeiro as questões econômicas: as grandes plantações e indústrias estatais foram planejadas apressadamente e provaram ser antieconômicas. A Serra Leoa, anteriormente exportador de arroz, tornou-se importador de arroz e o governo foi forçado a pedir um empréstimo do Fundo Monetário Internacional (FMI) de US\$7,5 milhões no final de 1966, além disso, a corrupção se instauraria profundamente no governo (HARRIS, 2014).

Após as novas eleições gerais em 1967, o candidato Siaka Stevens do CTP sobe ao poder oficialmente em 1968. Ele foi imediatamente confrontado com uma série de problemas potencialmente terminais que incluíam: a baixa governança estatal; a economia com sua excessiva dependência nos diamantes; dívidas; corrupção; forças armadas politizadas e com um gosto pelo poder; e um mandato 
eleitoral marginal desordenadamente inclinado para o norte; uma nação muito mais dividida ao longo do eixo norte-sul e uma relação ambivalente com o poder no campo exercido pelos chefes "tribais" (HARRIS, 2014).

Logo após a vitória de Stevens, o exército interveio e instaurou um governo militar por meio de um golpe, com o auxílio do Conselho de Reforma Nacional sob o comando do coronel Andrew JuxonSmith. Depois de um ano de governo, alguns soldados se amotinaram, prenderam seus oficiais e restauraram o governo parlamentar sob Stevens e o CTP. Os anos seguintes foram tempestuosos, o governo constantemente declarava estados de emergência e executava seus oponentes políticos.

Em 1971, Serra Leoa tornou-se uma república, com Stevens como presidente executivo. Enquanto isso, a economia se deteriorou, o suprimento de minério de ferro estava exausto e a maioria dos diamantes eram contrabandeados, privando, assim, o governo de receita. A insatisfação pública cresceu, liderada por protestos estudantis e a resposta de Stevens foi introduzir o regime de partido único, em 1978, algo que seu oponente anterior, Albert, havia tentado fazer em 1966, mas, sem obter sucesso (FYFE; SESAY; NICOL, 2018).

É de suma importância entender que a estratégia contida no pragmatismo de Stevens em eliminar e perseguir a oposição, seja nas forças armadas, na política partidária ou na sociedade, era sua maneira de se colocar no auge de um sistema clientelista. Sistema no qual tinha como base o comércio de diamantes que futuramente iria esgotar as fontes formais de recursos do Estado (HARRIS, 2014).

É, então, imprescindível entender as relações entre o período de dominação colonial da Serra Leoa e as práticas administrativas adotadas por Stevens, pois é apenas partindo desse contexto que se torna possível identificar as raízes do conflito que arrastou o país por um pouco mais de uma década.

Assim como enfatizou Asangna (2017), a guerra civil foi em grande parte resultado do sistema de administração clientelista que serviu de base para a fraqueza do Estado durante a administração do Congresso de Todas as Pessoas. Entretanto, não só a política do país permaneceu instável nas três primeiras décadas de independência, o crescimento socioeconômico foi igualmente defeituoso, e a guerra causou uma rápida regressão na estrutura estatal que já era debilitada (ASANGNA, 2017).

Sobre suas considerações acerca da guerra civil, Harris (2014) inicia o debate assinalando que, 0 Estado e as forças armadas de Serra Leoa não estavam em condições de, no início dos anos 9o, resistir a qualquer tipo de invasão ou insurreição. As forças armadas do país estavam profundamente debilitadas e possuíam uma capacidade pouca ou nenhuma capacidade de responder a ameaças, sejam estas de natureza interna ou externa.

Sem embargo, segundo os relatos de Wai (2012), em 23 de março de 1991, um bando de insurgentes armados atacou a cidade de Bomaru (distrito de Kailahun), na fronteira leste da Serra Leoa com a Libéria. Com uma força estimada entre sessenta e cem combatentes - armados com fuzis de assalto AK-47, metralhadoras automáticas e semiautomáticas e granadas de foguete - o grupo rapidamente 
invadiu a cidade antes de se retirar para Voinjama na Libéria, de onde haviam lançado seu ataque. A manobra deixou 2 oficiais (um major e tenente) da Força Militar da República da Serra Leoa e 11 civis mortos (WAl, 2012).

De acordo com o exame histórico de Harris (2014), a guerra civil na Serra Leoa mudou consideravelmente ao longo do tempo em termos dos principais atores, suas alianças, o formato do conflito e sua localização geográfica. Porém, o escrutínio dos acontecimentos da guerra em termos históricos propriamente ditos não é o objeto deste estudo, por isso, há que se considerar apenas os principais momentos do conflito a partir da classificação de Harris (2014), mas sem aprofundá-los.

Sem embargo, entende-se que a fase inicial da guerra se dá principalmente no período de $1991 \mathrm{a}$ 1996, e tem como principais atores a Frente Revolucionária Unida (FRU) e o exército nacional serra-leonês. A segunda fase começa com a eleição, em 1996, de Ahmad Tejan Kabbah, e continua com o período da junta exército-FRU em 1997-98, sendo que o Grupo de Monitoramento da Comunidade Econômica dos Estados da África Ocidental revida. A junta recua para o Norte e as manobras militares terminam com a invasão da capital Freetown em 6 de janeiro de 1999. A terceira fase é o começo do fim e inclui o Acordo de Lomé, as missões da ONU e da Inglaterra em 1999 e 2000 respectivamente. Há, também, as incursões das Forças Armadas Revolucionárias da Libéria na Libéria e na Guiné, as sanções da ONU contra o presidente da Libéria e apoiador da RUF, Charles Taylor, e os acordos finais de paz em 2001 (HARRIS, 2014).

Em suma, a Serra Leoa, por uma década de sua história, sofreu com uma guerra interna catastrófica que resultou em estagnação socioeconômica e política e vários custos humanos. De acordo com o relatório do Grupo de Análise de Dados da Benetech Human Rights e da Ordem dos Advogados Americanos, de 2006, a maioria das análises do conflito da Serra Leoa estima o total de mortes durante o conflito entre 50.000 e 75.000 .

Sendo que, as violações mais comuns durante o conflito foram o deslocamento forçado, a destruição e roubo de propriedade. Estima-se que 1,5 milhão de pessoas sofreram deslocamento e 430 mil sofreram destruição de propriedade. Houve uma estimativa de 146.000 ataques (de vários tipos) e aproximadamente 100.000 casos de privação de liberdade (GUBEREK et al, 2006).

Levando em conta, então, o número exacerbado de violações dos direitos fundamentais durante os pouco mais de 10 anos de conflito no país, há que se entender a importância do estabelecimento, em um primeiro momento, de algumas liberdades fundamentais no cenário pós-conflito. Portanto, a próxima sessão se encarregará de analisar o papel da sociedade civil organizada (mais especificamente das ONGs de direitos humanos serra-leoninas) no processo de reconhecimento e positivação destas liberdades no Acordo de Lomé, que formalmente pusera um término nas hostilidades.

\section{A ATUAÇÃO DA SOCIEDADE CIVIL ORGANIZADA DURANTE OS PROCESSOS DE NEGOCIAÇÃO DA PAZ - LIBERDADES FUNDAMENTAIS E O ACORDO DE LOMÉ:}


O Acordo de Paz de Lomé, de 1999, assinado entre as partes em conflito durante a guerra civil na Serra Leoa, foi um divisor de águas na história do país. Apesar das imperfeições, o Acordo desempenhou um papel significativo na cessação das principais operações de combate e hostilidades e na criação de instituições e regimes com implicações de longo alcance, tanto para a Serra Leoa quanto para a comunidade internacional (MUSTAPHA; BANGURA, 2010).

Sem embargo, sabe-se que as disposições sobre direitos humanos contidas no Acordo de Lomé devem-se ao que foi feito primeiramente no Acordo de Abidjan e, em particular, à mobilização de ONGs de direitos humanos e mecanismos locais (que ocasionalmente chamaremos de sociedade civil organizada). A atuação destas organizações foi especialmente avulta no final dos anos go (CONSELHO INTERNACIONAL DE POLÍTICA DE DIREITOS HUMANOS, 2006), quando contribuíram não apenas para com o avanço nas negociações da paz, mas para com o reconhecimento de algumas liberdades fundamentais no cenário pós-conflito.

A Serra Leoa tem um setor vibrante da sociedade civil com sólidas raízes históricas: ao longo da história moderna do país, várias formas de associações voluntárias e organizações cívicas têm desempenhado papéis fundamentais na aproximação das pessoas para com o bem comum. É possível identificar no país, de maneira geral, cinco tipos diferentes de associações voluntárias que atendiam às necessidades de seus representados: uniões tribais, sociedades amigas, associações profissionais, grupos de entretenimento e associações recreativas (KANYAKO, 2016).

Adotando a definição de Kanyako (2016, p. 165, tradução nossa), parte-se da premissa que a sociedade civil pode ser caracterizada enquanto composta por "organizações autónomas, voluntárias, sem fins lucrativos e formadas com o objetivo expresso de servir ao bem público"7. A sociedade civil local na Serra Leoa no geral é de suma importância, principalmente, quando há baixa governança estatal e o Estado em si não é capaz de satisfazer as necessidades mais básicas da população, como por muito tempo foi o caso da Serra Leoa.

Sobre o papel das ONGs no aceleramento do desenvolvimento, as considerações de Nishimuko (2009) são essenciais: em resposta à falha do desenvolvimento liderado pelo Estado (na Serra Leoa) durante as décadas de 1970 e 1980, o número de ONGs aumentou muito conjuntamente com suas conquistas. As ONGs estão envolvidas em uma vasta gama de áreas de desenvolvimento, como: melhorias na saúde, educação, agricultura, setores industriais, direitos humanos, além das questões de gênero e ambientais (NISHIMUKO, 2009).

Entretanto, o foco que se estabelecerá nesta sessão, é do papel da sociedade civil (que engloba também as ONGs) nos processos de negociação da paz e reconhecimento das liberdades fundamentais,

7Original: "autonomous, voluntary, nonprofit, and nonpolitical organizations formed with the expressed aim of serving the public good" (KANYAKO, 2016, p. 165). 
porém, sem negar a potencialidade destes organismos em atuarem em outros setores diversos da sociedade como fora exposto anteriormente.

É interessante explicitar que, além de fortalecer e encorajar vários atores não estatais, a guerra civil na Serra Leoa também levou à proliferação de grupos da sociedade civil. O número de grupos engajados em advocacia, monitoramento, resolução de conflitos e vários tipos de implementação de programas aumentou em visibilidade. De acordo com dados do Ministério do Desenvolvimento e Planejamento Econômico, uma média de 100 novas organizações se aplica para registro a cada ano (KANYAKO, 2016).

Além disso, a guerra empoderou grupos marginalizados, como mulheres, jovens, amputados e deficientes, para advogar por questões de seus interesses. Neste sentido, as habilidades de networking e colaboração que a sociedade civil organizada desenvolveu durante a guerra foi imprescindível e seus resultados podem ser sentidos até hoje (KANYAKO, 2016). Portanto, a existência e participação destes grupos nos processos de negociação da paz e na luta pelo reconhecimento das liberdades fundamentais fora de suma importância, assim como explicitado pelo Conselho Internacional de Política de Direitos Humanos (2006, p. 33-34):

[...] A dedicação de reportar e fazer lobby sobre os abusos dos direitos humanos teve impacto sobre como as questões passaram a ser tratadas, forçando o debate dos direitos humanos à mesa de negociações. A presença de atores de direitos humanos na mesa (tanto em papéis de negociação quanto de observadores) manteve a pressão para que essas questões permanecessem em pauta ${ }^{8}$.

Ou seja, o próprio levantamento da pauta dos direitos humanos nos processos de negociação da paz, talvez, não teria sido possível sem a atividade destes setores da sociedade preocupados em estabelecer freios à administração estatal no cenário pós-conflito frente às necessidades de reconhecimento das liberdades fundamentais uma vez usurpadas durante o conflito que arrastou o país por um pouco mais de uma década.

Além do mais, ao abordar a relação entre a guerra civil e as instituições locais, Bellows e Miguel (2006) chamam atenção para a atuação das ONGs também no processo de reconstrução do país no cenário pós-guerra, de acordo com eles, "o aumento da atividade das ONGs pareceu ser pelo menos parcialmente responsável pela rápida recuperação dos padrões de vida em áreas devastadas pela guerra" (BELLOWS; MIGUEL, 2006, p. 13) ${ }^{9}$.

Nishimuko (2009), também aponta outra iniciativa importante por parte da sociedade civil organizada no cenário pós-conflito: O papel das organizações não-governamentais e das organizações

\footnotetext{
8Original: "[...] The dedication to reporting and lobbying on human rights abuses impacted on how the issues for talks came to be framed, forcing human rights onto the table. The presence of human rights actors at the table (both in negotiation and observer roles), kept up the pressure for these issues to stay on the table".

9Original: "increased NGO activity appears to be at least partially responsible for the rapid recovery in living standards in war-torn areas".
} 
religiosas na realização da "Educação para Todos" na Serra Leoa, de acordo com a autora, a maior ONG internacional no setor da educação, o "Plan Sierra Leone" tem trabalhado para a renovação da educação no país e ajudou muitas escolas governamentais e outras escolas assistidas pelo governo em geral. Ou seja, além destes setores da sociedade civil contribuírem para o reconhecimento formal das liberdades fundamentais no Acordo de Paz de Lomé, também contribuíram com ações diretas em diferentes áreas onde haviam necessidades materiais e imateriais por parte da população como na infraestrutura e na educação.

No entanto, o Acordo de Lomé - que viria a reconhecer estas liberdades posteriormente - fora resultado de uma construção histórica de Acordos, sendo necessário entender os processos que levaram o seu surgimento e posterior formalização. Anterior ao Acordo de Paz de Lomé, outras tentativas foram feitas com o intuito de aproximar as partes do conflito em busca de um cessar-fogo e um fim definitivo das hostilidades.

A primeira reunião formal dos dois lados na guerra resultou no Acordo de Paz de Abidjan, assinado em novembro de 1996 pelo recém-eleito governo do Presidente Kabba e do líder da FRU, Foday Sankoh. O acordo pedia a cessação imediata de todos os combates, a anistia para todos os combatentes da FRU e a transformação desta em uma organização política (ZACK-WILLIAMS, 2010).

Após o fracasso do acordo de Abidjan, a próxima tentativa de conversa entre as duas partes conflitantes foi o Plano de Paz de Conakry, de 26 de junho de 1997, que estabeleceu um plano de sete pontos para devolver a Serra Leoa ao regime constitucional. Esse acordo também compartilhava uma característica importante tanto com o acordo de Abidjan quanto com o acordo de Lomé: a anistia para todas as partes envolvidas (ZACK-WILLIAMS, 2010).

As negociações da "Paz de Lomé" vieram na esteira dos acordos de Abidjan e Conakry, assim como em consequência do terrivel ataque à capital, em janeiro de 1999 pela FRU, no qual dezenas de residências particulares e prédios do governo foram destruídos, e milhares de civis inocentes foram mortos ou ficaram gravemente feridos (ZACK-WILLIAMS, 2010). Há que se considerar que o ataque de 1999 foi um fator importante que levou a comunidade internacional a levar a sério a situação na Serra Leoa, exortando o governo da Serra Leoa a clamar pelo cessamento das hostilidades.

O Acordo de Lomé, entre outras coisas, dá provisões acerca do reconhecimento e respeito das liberdades fundamentais em sua Parte $V$, intitulada "Direitos Humanos, Humanitarismo e Assuntos Socioeconômicos". O Artigo XXIV, que dispõe sobre a garantia e a promoção dos direitos humanos, explicita que: as liberdades básicas (ou fundamentais) civis e políticas hão de ser reconhecidas pelo ordenamento jurídico serra-leonino, incluindo o direito à vida, a proibição da tortura, o direito a um julgamento justo, a liberdade de expressão e associação e o direito de tomar partido nos assuntos públicos 
do Estado ${ }^{10}$. O Acordo também previa um certo número de organismos de acompanhamento/execução, porém, não previa qualquer disposição relativa à supervisão específica da implementação dos direitos fundamentais ali positivados (CONSELHO INTERNACIONAL DE POLÍTICA DE DIREITOS HUMANOS, 2006).

Entretanto, o Acordo está longe de ter resolvido todos os problemas que iriam emergir no contexto social serra-leonês pós-conflito. Conteh-Morgan (2016), por exemplo, analisa o nível de segurança e/ou insegurança humana na Serra Leoa desde o final da guerra em 2002. O autor argumenta que mesmo após a "reintegração" formal do Estado, ou seja, a devolução do poder central à figura estatal, muitas vezes ainda há a persistência de inseguranças relacionadas às necessidades humanas básicas. Quando os Estados ainda são incapazes de suprir estas demandas básicas, todo tipo de disfunção social que vai do banditismo aos protestos violentos continua (CONTEH-MORGAN, 2016).

E a realidade é que o Estado Serra-Leonino pós-conflito ainda não tinha capacidades materiais para atender algumas demandas da sociedade, e a insegurança alimentar é uma das principais causas de insegurança humana no país após o fim da guerra. De acordo com Conteh-Morgan (2016), principalmente pelo motivo do conflito ter destruído qualquer crescimento agrícola sustentável que já estava em vigor e esgotado boa parte dos recursos humanos da sociedade (devido à extensão temporal do conflito e o subsequente número de mortos).

É importante identificar estes pontos de defasagem na administração estatal relativa ao (não) suprimento das necessidades materiais da população, pois, de nada adianta o indivíduo na sociedade serra-leonesa ser contemplado com um rol extenso de liberdades fundamentais no plano formal, se não as pode colocar em prática na realidade material devido aos obstáculos postos pela escassez de recursos e pela manutenção de níveis altos de desigualdade, pois como afirmou Bobbio (2000, p. 490):

[...] todo ser humano deve ter o poder efetivo de traduzir em comportamentos concretos os comportamentos abstratos previstos pelas normas constitucionais que atribuem este ou aquele direito, e portanto deve possuir ele próprio, ou como quota de uma propriedade coletiva, bens suficientes para uma vida digna.

A garantia das liberdades no plano formal é de suma importância, pois tem a finalidade de proteger o indivíduo das eventuais ingerências do Estado (liberdade negativa) e também garantir que este participe efetivamente nos assuntos públicos e na administração estatal (liberdade positiva). Entretanto, como visto acima, é necessário que o Estado garanta que todo indivíduo tenha "[...] poder econômico suficiente para satisfazer algumas exigências fundamentais da vida material e espiritual, sem as quais a primeira liberdade é vazia, [e] a segunda é estéril" (BOBBIO, 2000, p. 490).

\footnotetext{
${ }^{10}$ Disponível em: <https://peacemaker.un.org/sites/peacemaker.un.org/files/SL_990707_LomePeaceAgreement.pdf> Acesso em: 10 maio 2018.
} 
Ainda relativo às capacidades materiais do Estado, Diana Szántó (2016) irá criticar o processo que ela veio a chamar de "NGOization", ou seja, o processo de empoderamento significativo da sociedade civil, mais especificamente das ONGs, no cenário pós-conflito. A autora defende que este processo acontece quando a sociedade civil se torna representada principalmente por ONGs e estas são investidas com um papel preponderante na organização da redistribuição econômica, do estabelecimento de objetivos políticos e na determinação da economia de um determinado país.

Em 2009, havia cerca de 3.000 ONGs (internacionais ou nacionais) registradas pelo Ministério das Finanças e Desenvolvimento Econômico da Serra Leoa. Devido ao papel protuberante que estas organizações da sociedade civil tiveram principalmente na economia pós-guerra do país, Diana denuncia que os capitais econômicos, simbólicos e sociais foram formados, acumulados e trocados ao mesmo tempo dentro desse sistema, assim, contribuindo para uma "recolonização cultural" e para a construção de uma elite de ONGs locais europeizadas, necessariamente influenciadas pelas expectativas dos doadores (DIANA SZÁNTÓ, 2016).

Ou seja, apesar da sociedade civil em geral, e das ONGs em específico, terem contribuído de maneira significativa nos processos de negociação da paz e na reestruturação material e imaterial do país no cenário pós-guerra civil, há uma linha de pensadores que critica o redirecionamento do poder para estes setores que não necessariamente representam os interesses da sociedade em sua totalidade, assim como apontou Diana Szántó (2016).

É importante assinalar, também, as bases da construção do sistema legal serra-leonino no cenário pós-conflito, pois é a partir dele que se pode analisar se as liberdades fundamentais reconhecidas pelo Acordo de Lomé puderam encontrar espaço, ou não, para sua justicialização efetiva. Para Corradi (2010), juntamente com as dificuldades apresentadas pelo legado deixado pelo conflito, existe no país uma realidade caracterizada pelo pluralismo jurídico "multicamadas", onde um sistema oficial de "direito tradicional" e direito consuetudinário opera ao lado de toda uma série de outras instâncias e atores da justiça informal. Além disso, a promoção das liberdades fundamentais ocorre em um contexto em que certos aspectos da organização social, como a justiça tradicional em suas diversas formas, estão frequentemente em desacordo com vários padrões de direitos humanos (CORRADI, 2010).

É possível considerar que, devido ao aparato legal do país possuir diversas ramificações, a insegurança jurídica pode ser um problema a curto e a longo prazo. Além disso, Jackson (2015) enfatiza que, embora algum desenvolvimento do sistema judicial tenha ocorrido em um estágio relativamente tardio no processo de reforma pós-conflito, a capacidade de usar esses tribunais não havia necessariamente se desenvolvido. O legado de um sistema judiciário falido que se acumulou durante vários anos ainda era sentido na Serra Leoa em 2008. Em particular, o sistema enfrenta uma enorme quantidade de casos, uma fraca manutenção de registros e espaço insuficiente nas prisões (JACKSON, 2015). 
Ainda consoante a Corradi (2010), cerca de $85 \%$ dos serra-leoneses estão sob a jurisdição do direito consuetudinário. Os tribunais locais têm poderes legais e formais para ouvir e determinar casos envolvendo questões de direito consuetudinário nas províncias. São presididos por um presidente, que é assistido por um vice-presidente e um painel de anciãos, por um funcionário e um oficial de justiça, que exerce funções administrativas e por uma agência de cumprimento da lei, a "polícia-chefia", sendo que o papel desta polícia é o de realizar prisões, apreensão de propriedade em falta de obediência e prisão (CORRADI, 2010).

Este papel da polícia ainda é frequentemente questionado na sociedade serra-leonesa e a demanda por reformas é constante, de maneira que, uma estrutura policial autoritária ameaça diretamente a realização das liberdades fundamentais. De acordo com M'Cormack, Vincent e Charley (2016), pesquisas de opinião mostraram que, embora o público pense que a força policial tenha melhorado, ela ainda é considerada uma instituição corrupta, por mais que reestruturações tenham sido adotadas, ainda há oficiais que se recusam a mudar. Há que se considerar também que, devido as altas taxas de desemprego, particularmente entre os jovens, existem altos índices de criminalidade, conflitos comunitários e assim por diante (M'CORMACK; VINCENT; CHARLEY, 2016).

Este índice de desemprego entre os jovens (e o consequente aumento nas taxas de criminalidade no país) se deve, entre outras coisas, à prévia participação destes jovens no conflito armado e sua subsequente não-reintegração na sociedade. De acordo com Tynes e Speed (2010), aproximadamente vinte mil crianças-soldados foram usadas durante a guerra civil na Serra Leoa entre 1991 e 2002 . Todos os lados recrutaram crianças - o Exército da Serra Leoa, a Frente Revolucionária Unida, o Conselho Revolucionário das Forças Armadas e a Força de Defesa Civil.

As partes que utilizaram crianças no combate, principalmente o governo, demonstraram pouco entusiasmo em realocar a juventude junto à vida civil, e a desmobilização de crianças-soldados foi, principalmente, iniciativa da comunidade internacional. Além disso, muitos ex-combatentes infantis não retornaram às suas raízes rurais, e escolheram a cidade como lar, formando uma nova juventude urbana (TYNES; SPEED, 2016). Ou seja, os jovens largaram as armas, mas tiveram poucas oportunidades de serem reintegrados à sociedade e muitos foram deslocados internamente e sofreram com diversos desafios socioeconômicos.

Todos estes problemas estão associados, dentre outras coisas, com a manutenção das desigualdades socioeconômicas que impulsionaram a eclosão do conflito interno, em 1991. Para Mustapha (2010), as desigualdades globais influenciam a persistência da violência estrutural através de vários mecanismos, incluindo, mas não se limitando, à socialização de políticas de liberalização econômica irrestritas, que tomaram lugar na Serra Leoa a partir dos anos 2000.

Para o autor, a vantagem indevida desfrutada por nações poderosas torna difícil para a Serra Leoa do pós-guerra competir no mercado global ou acessar o financiamento internacional necessário para 
projetos de desenvolvimento, ou seja, minimizar a violência estrutural e alcançar a paz positiva na Serra Leoa, que requer uma democratização significativa das estruturas globais que perpetuam as desigualdades (MUSTAPHA, 2010).

Em síntese, o que se pode constatar é que a atuação avulta da sociedade civil organizada na Serra Leoa, representada na maioria das vezes pelas ONGs locais e internacionais, contribuiu, em meio a críticas, para com os processos de negociação e afirmação da "paz negativa" (ou cessação das hostilidades) e reconhecimento formal de certos direitos e liberdades fundamentais pelo Acordo de Paz de Lomé.

Dito isto, fora possível identificar também que, nem o Acordo, nem as ONGs foram capazes de extinguir os problemas sociais e econômicos que nasceriam ou seriam reforçados no cenário pós-conflito, pois, tais questões são muito mais complexas. Portanto, a resolução de tais contendas demandaria ações conjuntas de diversos atores locais, regionais e internacionais, que por meio de uma governança conjunta poderiam lutar para libertar a Serra Leoa de suas amálgamas do passado de violência e desigualdade estruturais.

\section{CONSIDERAÇÕES FINAIS}

Esta pesquisa teve por objetivos identificar qual foi o grau de importância da sociedade civil organizada na luta pelo reconhecimento das liberdades fundamentais durante os processos de negociação da paz na Serra Leoa e na posterior formalização do Acordo de Lomé, assim como, analisar se, tais liberdades foram alcançadas materialmente ou não, no contexto social serra-leonês.

Quanto ao primeiro objetivo, fora possível identificar, por meio das fontes consultadas, que a sociedade civil organizada na Serra Leoa, principalmente as ONGs de direitos humanos (entre outras) locais e internacionais tiveram papel importante durante os processos de negociação da paz e cessação das hostilidades. E, além de forçarem a pauta de direitos humanos durante estes processos, conseguiram fazer com que as partes do Acordo de Paz Lomé reconhecessem e positivassem por meio deste instrumento um corpo de liberdades e direitos fundamentais bem estabelecido.

Entretanto, conforme as constatações obtidas em resposta ao segundo objetivo, foi possível identificar que, o governo serra-leonês, no contexto pós-conflito, possuía um sistema jurídico extremamente plural, que envolvia um sistema jurídico tradicional e outro consuetudinário, que englobava cortes locais e autoridades informais. Sem mencionar o fato de que lançava mão de uma polícia essencialmente corrupta e ocasionalmente abusiva, o que dificultou a garantia da segurança jurídica para todos os cidadãos serra-leonenses.

Também se constatou que, o país veio a sofrer com diversos empasses socioeconômicos no fim da guerra civil, como: a não-reintegração dos jovens combatentes junto ao seio da sociedade; a deterioração das atividades produtivas agrícolas; a dificuldade em executar políticas concretas de 
desenvolvimento e aplainamento das desigualdades sociais e entre outras razões nas quais dificultaram a transposição das liberdades do plano formal do direito para o plano material da vida em sociedade.

Reitera-se que, esta pesquisa não teve por objetivo esgotar as análises acerca da importância (e limitações) da atuação da sociedade civil durante os processos de negociação da paz e na luta pelo reconhecimento formal dos direitos e liberdades fundamentais. Porém, intentou-se abrir um precedente para que outras pesquisas analisem de maneira crítica a atuação da sociedade civil organizada em diferentes contextos nacionais e transnacionais, de maneira a identificar suas potencialidades e insuficiências.

* Artigo recebido em 12 mai 2018, aprovado em 10 set 2018.

\section{REFERENCIAS}

AKUDE, John Emeka. The failure and collapse of the African state: on the example of Nigeria. 2007. Disponível em: <http://fride.org/descarga/COM_Nigeria_ENG_sepo7.pdf>. Acesso em: 20 abr. 2018.

ASANGNA, Clotilde. An examination of the Sierra Leone war. African Journal Of Political Science And International Relations, [S.L.], v. 11, n. 5, p.103-111, maio 2017. Disponível em: <http://www.academicjournals.org/journal/AJPSIR/article-full-text-pdf/BgFE4256380g>. Acesso em: 21 abr. 2018.

BELLOWS, John; MIGUEL, Edward. War and Local Institutions in Sierra Leone. 2006. Disponível em: <http://cega.berkeley.edu/assets/miscellaneous_files/wgape/10_BellowsMiguel.pdf>. Acesso em: 11 maio 2018.

BERNARD, Vincent. Tactics, techniques, tragedies: A humanitarian perspective on the changing face of war. International Review Of The Red Cross, [S.L.], v. 97, n. 900, p.959-968, dez. 2015. Cambridge University Press (CUP). http://dx.doi.org/10.1017/s1816383116000497. Disponível em: <https://www.icrc.org/en/international-review/evolution-warfare>. Acesso em: 20 abr. 2018.

BOBBIO, Norberto. Teoria geral da política: a filosofia política e as lições dos clássicos. Rio de Janeiro: Elsevier, 2000.

CONSELHO INTERNACIONAL DE POLÍTICA DE DIREITOS HUMANOS. Negotiating Justice? Human Rights and Peace Agreements. Versoix: Atar Roto Press, 2006. 
CONTEH-MORGAN, Earl. Peacebuilding and Human Security in Postwar Sierra Leone: A Critical Analysis. In: MUSTAPHA, Marda; BANGURA, Joseph J. (Ed.). Sierra Leone beyond the Lomé Peace Accord. Nova lorque: Palgrave Macmillan, 2010. p. 133-144.

CORRADI, Giselle. Human Rights Promotion in Post Conflict Sierra Leone: Coming to Grips with Plurality in Customary Justice. The Journal Of Legal Pluralism And Unofficial Law, [S.L.], v. 42, n. 60, p.73-103, jan. 2010. Disponível em: <https://www.tandfonline.com/doi/abs/10.1080/07329113.2010.10756637>. Acesso em: 11 maio 2018.

DUIKER, William J.. Contemporary World History. 5. ed. Boston: Wadsworth, 2010.

FYFE, Christopher. 1787-1887-1987: Reflections on a Sierra Leone Bicentenary. Africa: Journal of the International African Institute, Sierra Leone, v. 57, n. 4, p.411-421, jan. 1987. Disponível em: <https://www.jstor.org/stable/1159891?seq=1\#page_scan_tab_contents>. Acesso em: 06 maio 2018.

GUBEREK, Tamy et al. Truth and Myth in Sierra Leone: An Empirical Analysis of the Conflict, 1991-2000. 2006. Benetech Human Rights Data Analysis Group. Disponível em: <https://hrdag.org/wpcontent/uploads/2013/01/Benetech-Truth-Myth-Sierra-Leone-1991-2000.pdf>. Acesso em: og maio 2018.

HARRIS, David. Sierra Leone: A Political History A. Nova lorque: Oxford University Press, 2014.

JACKSON, P.. Whose Justice in Sierra Leone?: Power, Security and Justice in Post-Conflict Reconstruction. In: AINLEY, K.; FRIEDMAN, R.; MAHONY, C. (Ed.). Evaluating Transitional Justice: Rethinking Peace and Conflict Studies. Londres: Palgrave Macmillan, 2015. p. 197-215.

KANYAKO, Vandy. Civil Society and Democratized Peace in Postwar Sierra Leone. In: MUSTAPHA, Marda; BANGURA, Joseph J. (Ed.). Democratization and Human Security in Postwar Sierra Leone. Nova lorque: Palgrave Macmillan, 2016. p. 163-176.

M'CORMACK, Freida Ibiduni; VINCENT, James B. M.; CHARLEY, Joseph P. Chris. Reconciling Police Reform and Local Security Provision in Postconflict Sierra Leone. In: MUSTAPHA, Marda; BANGURA, Joseph J. (Ed.). Democratization and Human Security in Postwar Sierra Leone. Nova lorque: Palgrave Macmillan, 2016. p. 59-80.

MUSTAPHA, Marda. Global Inequalities and Peace in Postwar Sierra Leone. In: MUSTAPHA, Marda; BANGURA, Joseph J. (Ed.). Sierra Leone beyond the Lomé Peace Accord. Nova lorque: Palgrave Macmillan, 2010. p. 145-160.

MUSTAPHA, Marda; BANGURA, Joseph J.. Introduction. In: MUSTAPHA, Marda; BANGURA, Joseph J. (Ed.). Sierra Leone beyond the Lomé Peace Accord. Nova lorque: Palgrave Macmillan, 2010. p. 1-16.

NISHIMUKO, Mikako. The role of non - governmental organisations and faith - based organisations in achieving Education for All: the case of Sierra Leone. Compare: A Journal of Comparative and International 
Education, [S.L.], v. 39, n. 2, p.281-295, mar. 2009. Disponível em: <https://goo.gl/ZmbReY>. Acesso em: 10 maio 2018.

RAMONET, Ignacio. Geopolítica do Caos. 3. ed. Petrópolis: Vozes, 1999.

SESAY, Shekou M.; NICOL, Davidson S.H.W.; FYFE, Christopher. Sierra Leone. 2018. Disponível em: <https://www.britannica.com/place/Sierra-Leone>. Acesso em: 06 maio 2018.

SZÁNTÓ, Diana. The NGOization of Civil Society in Sierra Leone: A Thin Dividing Line between Empowerment and Disempowerment. In: MUSTAPHA, Marda; BANGURA, Joseph J. (Ed.). Democratization and Human Security in Postwar Sierra Leone. Nova lorque: Palgrave Macmillan, 2016. p. $133-162$.

TYNES, Robert; SPEED, Clarke. The 1999 Lomé Peace Accord and Child Combatants: For Di People? For Di Pikin? Or for the International Community?. In: MUSTAPHA, Marda; BANGURA, Joseph J. (Ed.). Sierra Leone beyond the Lomé Peace Accord. Nova lorque: Palgrave Macmillan, 2010. p. 49-68.

WAI, Zubairu. Epistemologies of African Conflicts: Violence, Evolutionism, and the War in Sierra Leone. Nova lorque: Palgrave Macmillan, 2012.

ZACK-WILLIAMS, Tunde. Sierra Leone beyond Lomé: Challenges and Failures. In: MUSTAPHA, Marda; BANGURA, Joseph J. (Ed.). Sierra Leone beyond the Lomé Peace Accord. Nova lorque: Palgrave Macmillan, 2010. p. 17-34. 